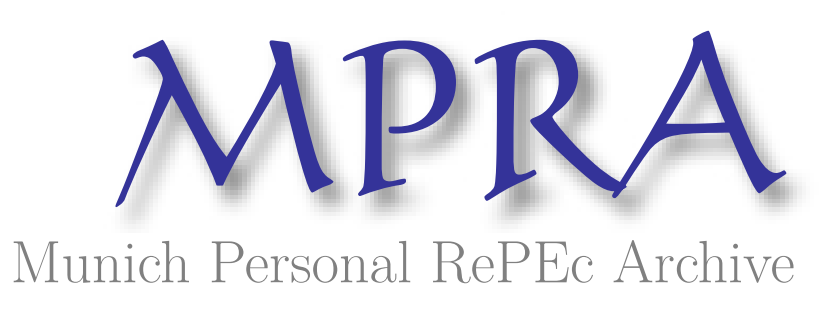

\title{
A dynamic factor model of the coincident indicators for the US transportation sector
}

Lahiri, Kajal and Yao, Wenxiong

Department of Economics, University at Albany-SUNY, Albany, NY 12222, USA

August 2004

Online at https://mpra.ub.uni-muenchen.de/22360/

MPRA Paper No. 22360, posted 29 Apr 2010 00:18 UTC 


\title{
A Dynamic Factor Model of the Coincident Indicators for the U.S. Transportation Sector
}

\author{
Kajal Lahiri* and Wenxiong Yao \\ Department of Economics \\ University at Albany-SUNY \\ Albany, NY 12222 \\ U.S.A
}

Running title: Transportation Coincident Index

\section{Abstract}

This paper studies the business cycle features of the transportation sector using dynamic factor models. The transportation reference cycles peak ahead of the economic cycles, but lag by a few months at troughs. The asymmetric relationship between these two suggests the usefulness of transportation in monitoring business cycles.

\footnotetext{
* Corresponding author. Department of Economics, University at Albany-SUNY, Albany, NY 12222. Tel: (518) 442-4758; Email: klahiri@albany.edu.
} 


\section{INTRODUCTION}

Transportation, being an important service-providing sector, represents a significant part of the U.S. economy. More importantly, transportation plays a vital role in facilitating economic activity between sectors and across regions. Ghosh and Wolf (1997), in examining the importance of geographical and sectoral shocks in the U.S. business cycles, find that transport is one of sectors highly correlated with intra-state and intra-sector shocks, and is thus crucial in the propagation of business cycles. Interestingly, a number of transportation indicators were included as part of the twenty-one cyclical indicators in the original NBER lists by Mitchell and Burns (1938) and Moore (1961, pp. 184-261). Further efforts to study the role of transportation in monitoring modern business cycles were hindered largely due to the discontinuation of many transportation indicators such as freight carloadings in the 1950s and the 1960s. For more information on the history of cyclical indicators, see the NBER Macrohistory database available online (Feenberg and Miron, 1997).

Lahiri and Yao (2004) have explored the macroeconomic forecasting potential of a monthly experimental index measuring the aggregate output of the transportation sector developed in Lahiri et al. (2003). This transportation services index (TSI), now being produced by U.S. Department of Transportation, utilizes eight series on freight and passenger movements from airlines, rail, waterborne, trucking, transit and pipelines (NAICS codes 481-486) covering around 90\% of total for-hire transportation during 1980-2000. TSI is a chained Fisher-ideal index, and is methodologically similar to the Industrial Production (IP) index, which is one of the four coincident indicators for the aggregate economy. ${ }^{1}$ Following the conventional economic indicator analysis (Zarnowitz, 1992), we can use TSI together with other coincident indicators from transportation to study the business cycles characteristics of this sector, and its relationship to the aggregate economy. This paper applies dynamic factor models with regime switching

\footnotetext{
${ }^{1}$ Gordon (1992) and Bosworth (2001) have provided valuable insights into the different methodologies and data that BEA and BLS use to construct alternative annual transportation output series. A comparison suggests that these annual output measures reflect the long-term trends of TSI, and that the latter is superior in reflecting the cyclical movements in the transportation sector.
} 
(Kim and Nelson, 1998) and without regime switching (Stock and Watson, 1991) to estimate the composite coincident index (CCI) for the transportation sector.

\section{THE MODEL AND ESTIMATES}

Given a set of coincident indicators $Y_{i t}$, their growth rates can be explained by an unobserved common factor $\Delta C_{t}$, interpreted as growth in $\mathrm{CCI}$, and some idiosyncratic dynamics. This defines the measurement equation for each component:

$$
\Delta Y_{i t}=\gamma_{i} \Delta C_{t}+e_{i t}
$$

where $\Delta Y_{i t}$ is logged first difference in $Y_{i t}$. In the state-space representation, $\Delta C_{t}$ itself is to be estimated. In the transition equations, both the index $\Delta C_{t}$ and $e_{i t}$ are processes with $\mathrm{AR}$ representations driven by noise terms $w_{t}$ and $\varepsilon_{i t}$ respectively:

$$
\begin{aligned}
& \Phi(L)\left(\Delta C_{t}-\mu_{s t}-\delta\right)=w_{t}, \\
& \Psi(L) e_{i t}=\varepsilon_{i t} .
\end{aligned}
$$

These two noise terms are assumed to be independent of each other. The transitions of different regimes $\left(\mu_{s t}\right)$, incorporated in (2), are governed by a Markov process:

$$
\begin{aligned}
& \mu_{s t}=\mu_{0}+\mu_{1} S_{t}, S_{t}=\{0,1\}, \mu_{1}>0, \\
& \operatorname{Prob}\left(S_{t}=1 \mid S_{t-1}=1\right)=p, \operatorname{Prob}\left(S_{t}=0 \mid S_{t-1}=0\right)=q .
\end{aligned}
$$

Equations (1) (3) define the dynamic factor model while (4) (5) add a nonlinear regime switching feature to it. Following the NBER tradition and Layton and Moore (1989), we use four conventional coincident indicators to define the current state of U.S. transportation sector. They are: TSI $\left(Y_{l t}\right)$ as defined earlier, real aggregate payrolls of transportation workers $\left(Y_{2 t}\right)$, real personal consumption expenditure on transportation services $\left(Y_{3 t}\right)$, and total employment $\left(Y_{4 t}\right)$ in this sector. These indicators, plotted in Figure 1, reflect information on output, income, sales, and labor usage in the transportation sector.

For the sake of comparison, we first constructed a coincident index for the transportation sector using the model-free NBER approach, see Conference Board (2001). ${ }^{2}$ Using the index of concordance proposed by Harding and Pagan (2002), we

\footnotetext{
${ }^{2}$ This nonparametric approach includes four steps: 1) month-to-month changes $\left(x_{t}\right)$ are computed for each component $\left(X_{t}\right)$ using the conventional formula; 2 ) the month-to-month changes are adjusted to equalize the volatility of each component using the standardization factors; 3 ) the level of the index is computed using
} 
found that the specific cycles of each series are highly synchronized (all values were in excess of 0.60) with the transportation reference cycle based on the NBER index. To implement the Kim-Nelson model, we used priors from the estimated Stock-Watson model. Priors for regime switching parameters were obtained from information provided by the NBER index. Both models were estimated using computer routines described in Kim and Nelson (1998). Unlike the Stock-Watson (1989) model specification for the aggregate economy, personal consumption expenditure and employment in transportation appear to be somewhat lagging to the current state of transportation.

The final specification and parameter estimates from Stock-Watson and KimNelson models are reported in Table 1. The two sets of estimates are close except that the sum of the AR coefficients for the state variable in the Stock-Watson model is significantly higher, implying more state dependence in the resulting index. This difference is complemented by a much larger role that employment plays in the KimNelson model. The latter model also distinguishes between two clear-cut regimes of positive and negative growth rates. The estimated transportation CCIs from these two models are plotted against the NBER index in Figure 2. Compared to the Kim-Nelson index, the Stock-Watson index agrees more closely with the NBER index throughout the period. Despite differences in their model formulations and in minor details, their cyclical movements appear to be very similar to one another and synchronized well with the NBER-defined recessions for the economy (the shaded areas).

\section{RELATION WITH BUSINESS CYCLES}

NBER dating algorithm described in Bry and Boschan (1971) is employed to identify the turning points for four coincident indicators and the NBER index. The NBER procedure to define recessions for U.S. economy involves visually identifying clusters of turning points of all series and minimizing the distance between the turning points in each cluster (Layton and Moore, 1989). Following these standard steps, we define the chronology of cycles in the U.S. transportation sector since January 1979 that includes four major recessions: 1979:03 1980:08, 1981:01 1983:02, 1990:05 1991:06, and 2000:11

the symmetric percent change formula; and 4) the index is re-based to be 100 in 1996 to make a formal NBER index. 
2001:12. These periods are compared against the NBER-defined recessions of the aggregate economy in Table 2. Overall, there is a one-to-one correspondence between cycles of the transportation sector and those of the overall economy. However, the relationship between transportation and the economy is asymmetric at peaks and troughs. ${ }^{3}$ Specifically, the transportation sector peaked ahead of the economy by almost 6 months on the average, while at troughs it lagged by two months. In other words, recessions in the transportation sector lasted longer that the economy-wide recessions by almost 8 months. Thus, the cycles of this sector can potentially be used to confirm the NBER dating of U.S. recessions.

The above analysis is based on the nonparametric procedure practiced by the NBER Dating Committee. Alternatively, reference cycles can be defined from the probability of recessions implied by the regime-switching model of Kim and Nelson (1998). Figure 3 depicts the posterior probability that transportation sector is in a recession as inferred from the Kim-Nelson model estimation. The darker shaded areas represent the NBER-defined recessions for the U.S. economy, while the lightly shaded areas represent recessions in the U.S. transportation sector as defined in Table 2. If we define the transportation recessions parametrically by taking the first month that the probability begins to rise (drop) as the trough (peak), the resultant chronology would be very similar to shaded areas representing transportation recessions defined earlier. The probabilities in Figure 3 show that, corresponding to each of the four economy-wide recessions defined by NBER, there is a recession in the transportation sector. The KimNelson recession probabilities also indicate that the transportation recessions are consistently longer in duration than the economy-wide recessions. Figure 3 suggests that the latest recession in the U.S. transportation sector ended in December 2001, which is just one month after the recently announced NBER trough of the economic recession that began in March 2001. Interestingly, the finding on the longer duration of transportation recessions is very similar to that in Moore (1961, pp. 48-51), who used only railway freight data for his conclusion.

\footnotetext{
${ }^{3}$ Interestingly, a similar asymmetry also exists between inventory and business cycles, see Zarnowitz (1992, p. 336) and Humphreys et al. (2001).
} 


\section{CONCLUDING REMARKS}

This paper reports certain business cycle features of the U.S. transportation sector using economic indicator analysis. Four coincident indicators are selected to measure labor inputs, production, income and spending in this sector. Then composite indexes of these coincident indicators are created using both the NBER non-parametric method and dynamic factor models. The resulting indexes are seen to be very similar. We find a close correspondence between the recessions in the transportation sector and those in the aggregate economy. However, duration of the transportation recessions is longer than that of economy-wide recessions by almost 8 months. Further research is needed to explain the asymmetric lead/lag relationship between the two reference cycles at peaks and troughs.

\section{ACKNOWLEDGEMENTS}

This study has been supported by grants from the Bureau of Transportation Statistics, U.S. Department of Transportation during 2001-2003. However, the contents of this paper reflect the views of the authors, who are responsible for the facts and the accuracy of the information presented herein.

\section{REFERENCES}

Bosworth, B. (2001) Output and Productivity in the Transportation Sector: An Overview, paper presented at 'Workshop on Transportation Output and Productivity,' The Brookings Institution.

Bry, G. and Boschan, C. (1971) Cyclical Analysis of Time Series: Selected Procedures and Computer Programs, NBER Technical Paper 20.

Conference Board (2001) Calculating the Composite Indexes, www.conference-board.org, revised 01/01.

Feenberg, D. and Miron, J. (1997) Improving the Accessibility of the NBER's Historical Data, Journal of Business and Economic Statistics, Vol. 15(3), July, 293-299.

Ghosh, A.R. and Wolf, H.C. (1997) Geographical and Sectoral Shocks in the U.S. Business Cycle, NBER Working Paper \# 6180, September. 
Gordon, R.J. (1992) Productivity in the Transportation Sector, in Griliches, Z. (ed.),

Output Measurement in the Service Sectors, Chicago: University of Chicago Press, $371-428$.

Hamilton, J.D. (1989) A New Approach to the Economic Analysis of Nonstationary Time Series and the Business Cycle, Econometrica, Vol. 57, 357-384.

Harding, D. and Pagan, A. (2002) Dissecting the Cycle: a Methodological Investigation, Journal of Monetary Economics, Vol. 49, 365-381.

Humphreys, B.R, Maccini, L.J., and Schuh, S. (2001) Input and Output Inventories, Journal of Monetary Economics, Vol. 47, 347-374.

Kim, C.J. and Nelson, C.R. (1998) Business Cycle Turning Points, A New Coincident Index, and Tests of Duration Dependence Based on A Dynamic Factor Model with Regime Switching, The Review of Economics and Statistics, Vol. 80(2), 188-201.

Lahiri, K., Stekler, H.O., Yao, W. and Young, P. (2003) Monthly Output Index for the US Transportation Sector, Journal of Transportation and Statistics, Vol. 6(2/3), 1-37.

Lahiri, K. and Yao W. (2004) The Predictive Power of an Experimental Transportation Output Index. Applied Economics Letters, Vol. 11(3), 149-152.

Layton, A. and Moore, G.H. (1989) Leading Indicators for the Service Sector, Journal of Business and Economic Statistics, Vol. 7(3), 379-386.

Mitchell, W.C. and Burns, A.F. (1938) Statistical Indicators of Cyclical Revivals, reprinted in Moore, G.H. (ed.) Business Cycle Indicators, Volume I. Princeton, New Jersey: Princeton University Press for NBER, 1961, 162-183.

Moore, G.H. (1961) Business Cycle Indicators, Volume I. Princeton, New Jersey: Princeton University Press for NBER.

Stock, J.H. and Waston, M.W. (1991) A Probability Model of the Coincident Economic Indicators, in Lahiri, K. and Moore, G.H. (eds), Leading Economic Indicators: New Approaches and Forecasting Records, (Cambridge University Press, Cambridge), 6389.

Zarnowitz, V. (1992) Business Cycles: Theory, History, Indicators, and Forecasting, The University of Chicago Press. 
Figure 1

Coincident Indicators for the U.S. Transportation Sector

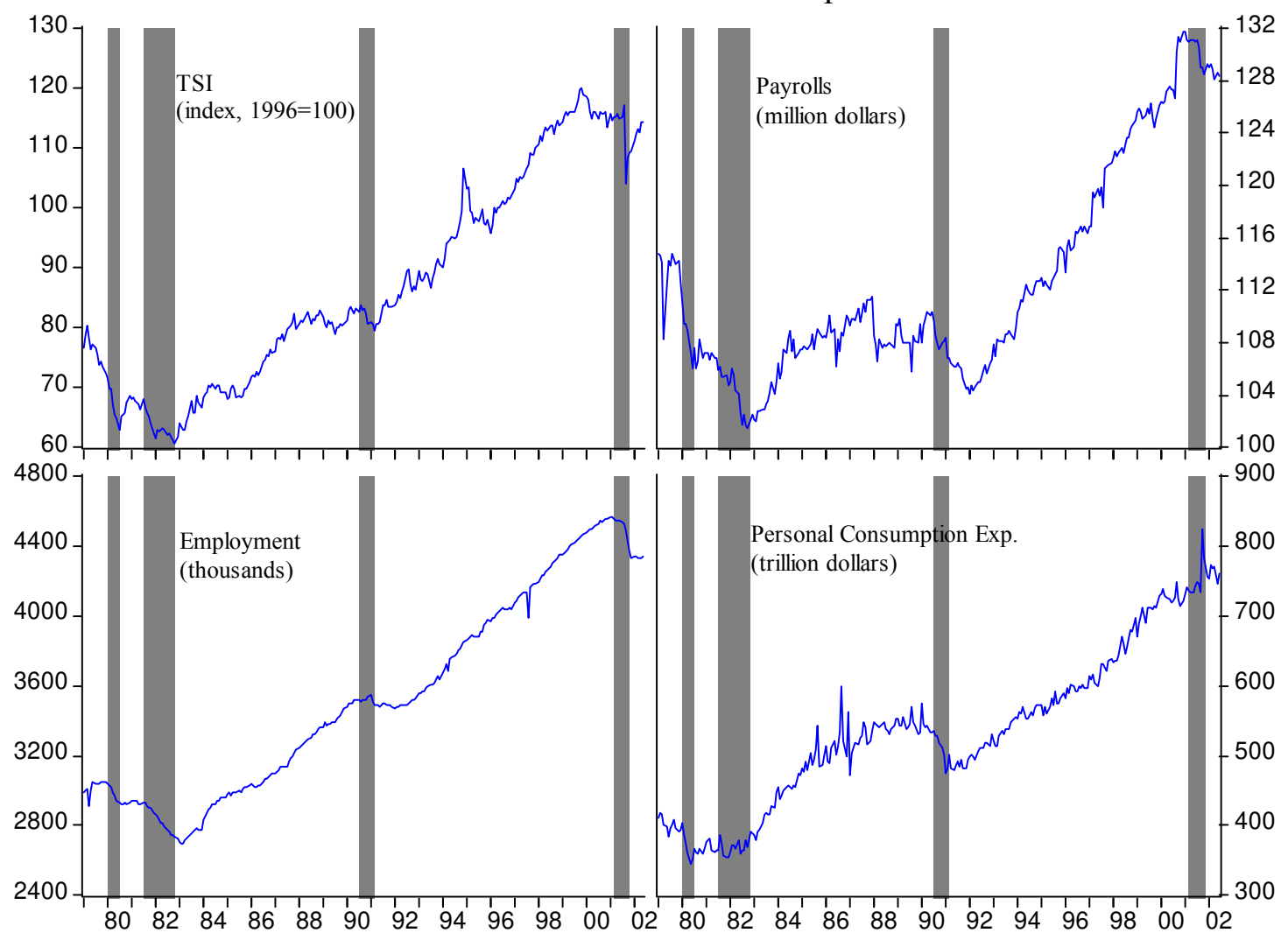

*Shaded areas represent NBER-defined recessions for the U.S. economy 
Figure 2

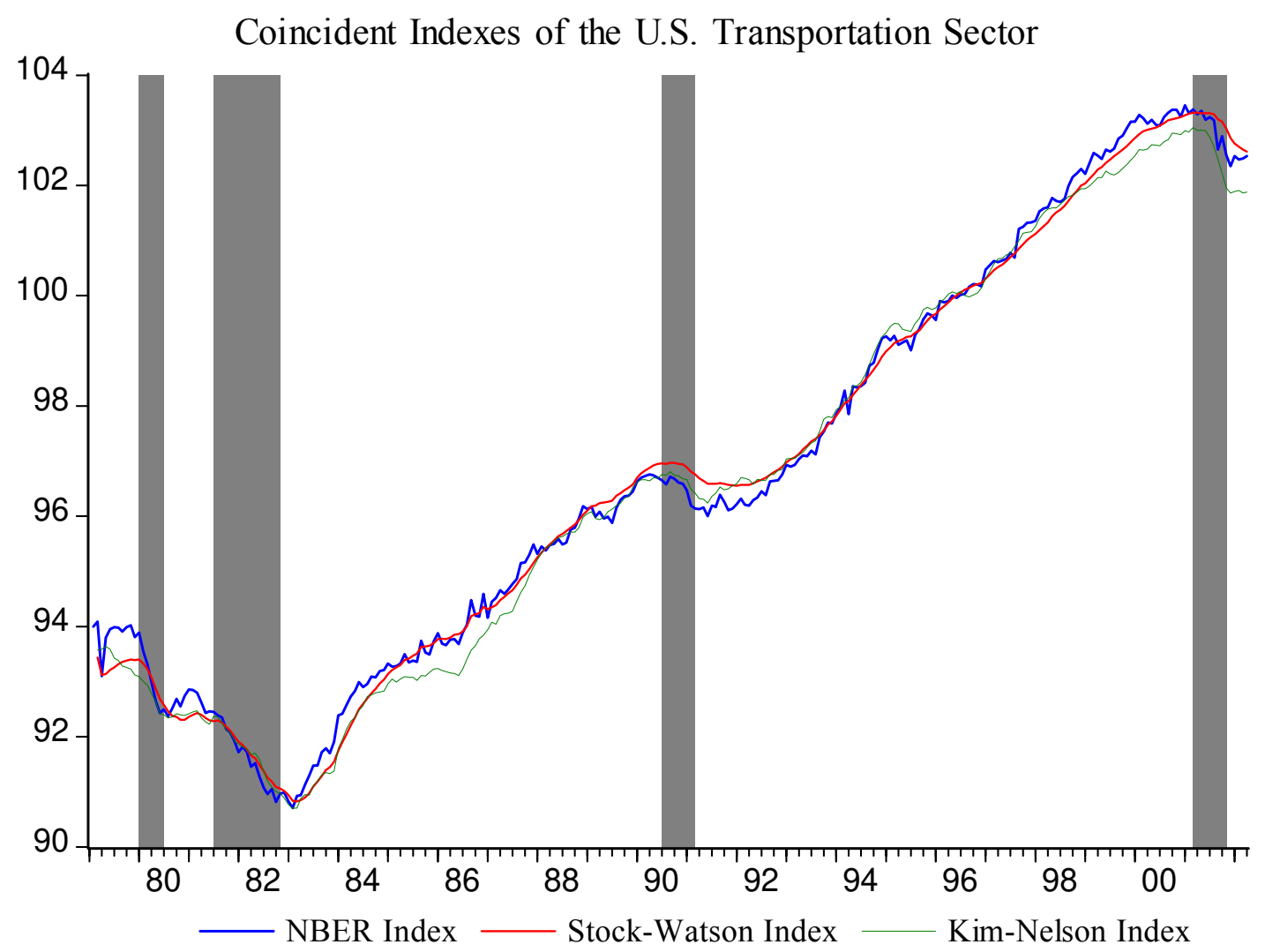

*Shaded areas represent NBER-defined recessions for the U.S. economy 
Figure 3

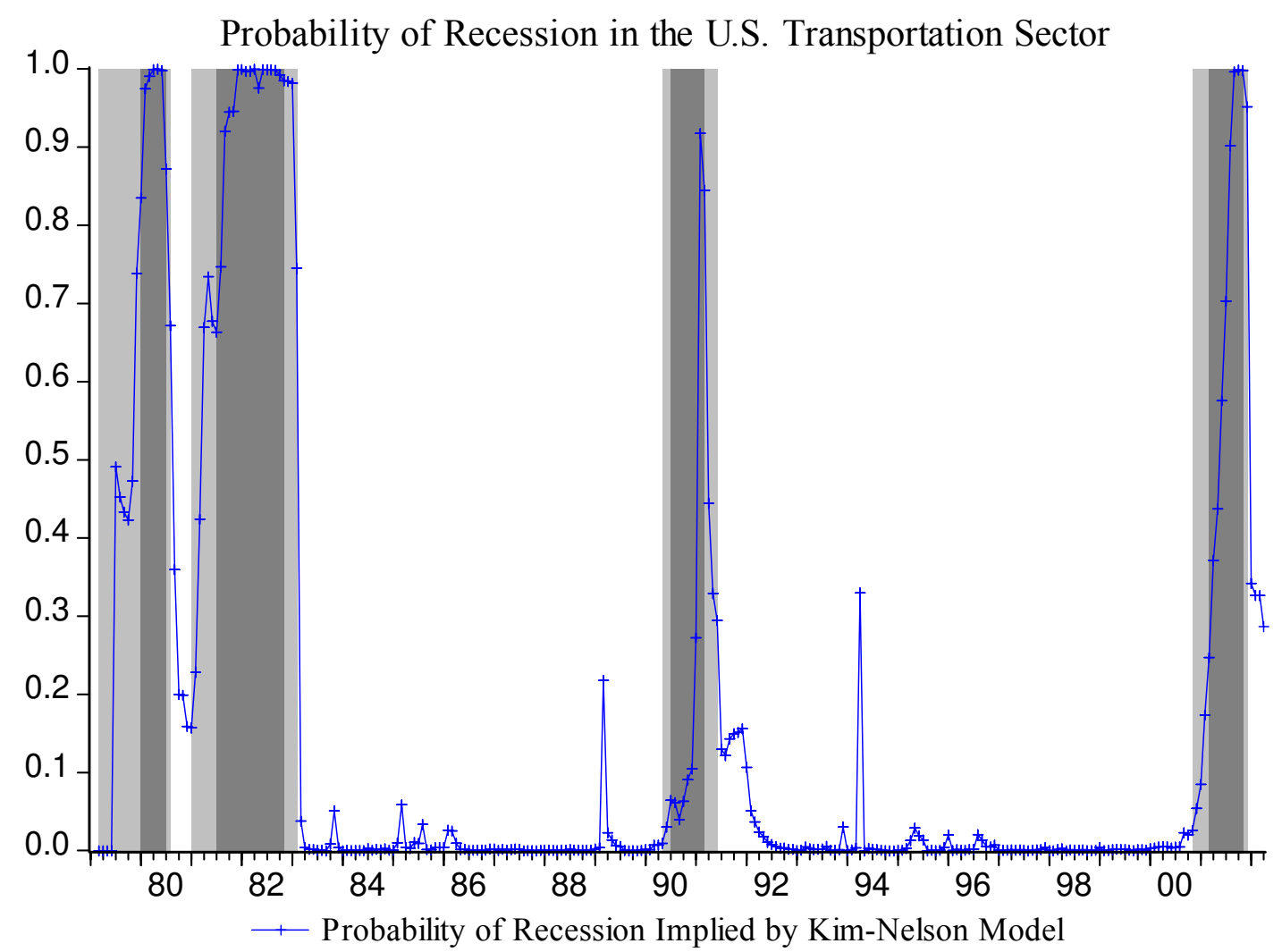

* Darker shaded areas represent NBER-defined recessions for the U.S. economy; lightly shaded areas represent recessions of the U.S. transportation sector. 
Table 1 Estimates of the Transportation Coincident Index Models

\begin{tabular}{|c|c|c|c|c|c|c|c|}
\hline \multirow[t]{3}{*}{ Variables } & \multirow[t]{3}{*}{ Parameters } & \multicolumn{2}{|c|}{ Stock-Watson Model } & \multicolumn{4}{|c|}{ Kim-Nelson Model } \\
\hline & & & & \multirow[t]{2}{*}{ Prior } & \multicolumn{3}{|c|}{ Posterior } \\
\hline & & Estimate & s.e. & & Mean & s.e. & Median \\
\hline$\Delta C_{t}$ & $\Phi_{1}$ & 0.775 & 0.167 & 0.775 & 0.127 & 0.119 & 0.114 \\
\hline (State Variable) & $\Phi_{2}$ & 0.107 & 0.162 & 0.107 & 0.121 & 0.085 & 0.124 \\
\hline$\Delta Y_{1 t}$ & $\gamma_{1}$ & 0.171 & 0.057 & 0.1 & 0.136 & 0.028 & 0.136 \\
\hline \multirow[t]{3}{*}{ (Output) } & $\varphi_{11}$ & -0.519 & 0.067 & -0.2 & -0.637 & 0.057 & -0.638 \\
\hline & $\varphi_{12}$ & -0.067 & 0.017 & 0 & -0.401 & 0.057 & -0.401 \\
\hline & $\sigma_{1}^{2}$ & 5.181 & 0.480 & 2 & 0.652 & 0.057 & 0.648 \\
\hline$\Delta Y_{2 t}$ & $\gamma_{2}$ & 0.148 & 0.048 & 0.1 & 0.173 & 0.042 & 0.172 \\
\hline \multirow[t]{2}{*}{ (Payrolls) } & $\varphi_{21}$ & -0.162 & 0.077 & -0.1 & -0.216 & 0.061 & -0.216 \\
\hline & $\sigma_{2}^{2}$ & 2.107 & 0.210 & 2 & 0.782 & 0.071 & 0.778 \\
\hline$\Delta Y_{3 t}$ & $\gamma_{3}$ & 1.485 & 0.631 & 1.5 & 0.059 & 0.060 & 0.059 \\
\hline (Personal & $\gamma_{31}$ & -1.364 & 0.626 & -1.4 & -0.041 & 0.059 & -0.039 \\
\hline Consumption & $\varphi_{31}$ & -0.149 & 0.122 & -0.1 & -0.388 & 0.060 & -0.388 \\
\hline Exp.) & $\sigma_{3}^{2}$ & 2.443 & 1.831 & 2 & 0.849 & 0.076 & 0.844 \\
\hline$\Delta Y_{4 t}$ & $\gamma_{4}$ & 0.110 & 0.021 & 0.1 & 0.548 & 0.081 & 0.557 \\
\hline \multirow[t]{8}{*}{ (Employment) } & $\varphi_{41}$ & -0.006 & 0.357 & -0.1 & -0.025 & 0.084 & -0.026 \\
\hline & $\sigma_{4}^{2}$ & 0.072 & 0.015 & 2 & 0.125 & 0.081 & 0.120 \\
\hline & $\mathrm{P}_{00}$ & & & 0.967 & 0.926 & 0.066 & 0.945 \\
\hline & $\mathrm{P}_{11}$ & & & 0.986 & 0.985 & 0.012 & 0.988 \\
\hline & $\mu_{0}$ & & & -0.869 & -1.822 & 0.554 & -1.727 \\
\hline & $\mu_{1}$ & & & 0.745 & 2.208 & 0.580 & 2.110 \\
\hline & $\delta$ & & & - & 0.356 & 0.038 & 0.359 \\
\hline & $\mu_{0+} \mu_{1}$ & & & - & 0.385 & 0.132 & 0.385 \\
\hline
\end{tabular}


Table 2 Comparisons of Two Reference Cycles

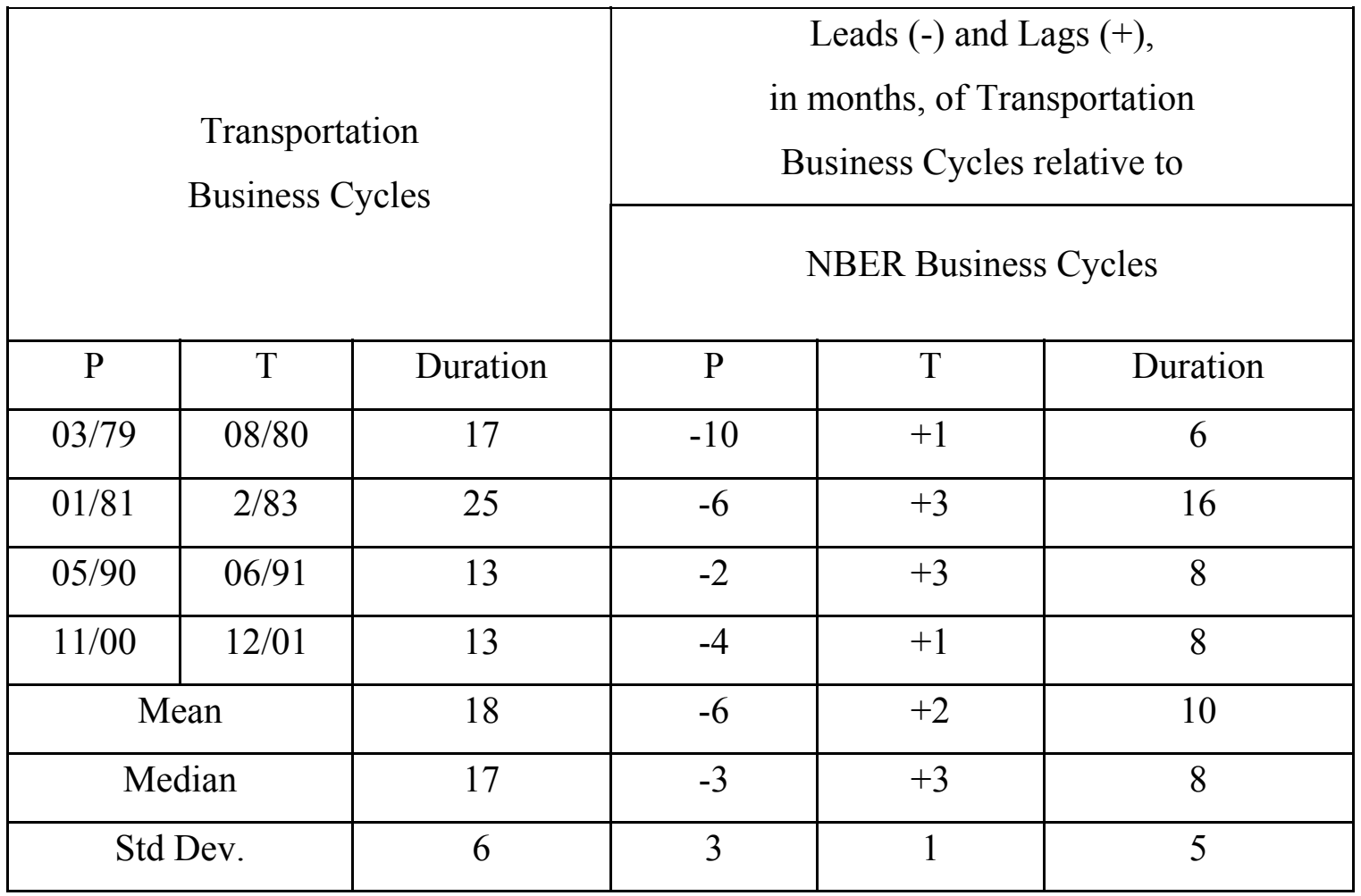

